\title{
Rain Splash Dispersal of Gibberella zeae Within Wheat Canopies in Ohio
}

\author{
P. A. Paul, S. M. El-Allaf, P. E. Lipps, and L. V. Madden
}

Department of Plant Pathology, The Ohio State University, Ohio Agricultural Research and Development Center, Wooster 44691. Accepted for publication 13 August 2004.

\section{ABSTRACT}

Paul, P. A., El-Allaf, S. M., Lipps, P. E., and Madden, L. V. 2004. Rain splash dispersal of Gibberella zeae within wheat canopies in Ohio. Phytopathology 94:1342-1349.

Rain splash dispersal of Gibberella zeae, causal agent of Fusarium head blight of wheat, was investigated in field studies in Ohio between 2001 and 2003. Samplers placed at 0, 30, and $100 \mathrm{~cm}$ above the soil surface were used to collect rain splash in wheat fields with maize residue on the surface and fields with $G$. zeae-infested maize kernels. Rain splash was collected during separate rain episodes throughout the wheat-growing seasons. Aliquots of splashed rain were transferred to petri dishes containing Komada's selective medium, and G. zeae was identified based on colony and spore morphology. Dispersed spores were measured in $\mathrm{CFU} / \mathrm{ml}$. Intensity of splashed rain was highest at $100 \mathrm{~cm}$ and ranged from 0.2 to $10.2 \mathrm{~mm} \mathrm{~h}^{-1}$, depending on incident rain intensity and sampler height. Spores were recovered from splash samples at all heights in both locations for all sampled rain events. Both macroconidia and ascospores were found based on microscopic examination of random samples of splashed rain. Spore density and spore flux density per rain episode

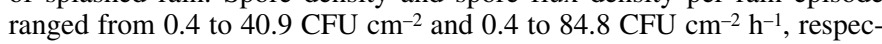
tively. Spore flux density was higher in fields with $G$. zeae-infested maize kernels than in fields with maize debris, and generally was higher at 0 and $30 \mathrm{~cm}$ than at $100 \mathrm{~cm}$ at both locations. However, on average, spore flux density was only $30 \%$ lower at $100 \mathrm{~cm}$ (height of wheat spikes) than at the other heights. The log of spore flux density was linearly related to the $\log$ of splashed rain intensity and the $\log$ of incident rain intensity. The regression slopes were not significantly affected by year, location, height, and their interactions, but the intercepts were significantly affected by both sampler height and location. Thus, our results show that spores of G. zeae were consistently splash dispersed to spike heights within wheat canopies, and splashed rain intensity and spore flux density could be predicted based on incident rain intensity in order to estimate inoculum dispersal within the wheat canopy.

Additional keywords: Fusarium graminearum, spore dissemination.
Fusarium head blight, caused predominantly by Gibberella zeae (Schwein.) Petch (anamorph: Fusarium graminearum Schwabe) in North America, is a limiting factor in most wheat and barley production regions of the world. Over the years, several epidemics of varying intensities have occurred in many wheat-production regions, leading to substantial yield losses $(2,26,30)$. Losses result from reduction in kernel size and weight, reduced seed germination, seedling blight, and poor stands $(2,42)$. Mycotoxins produced by G. zeae may lead to even further economic losses for agriculture, because they cause vomiting, feed refusal, and lower weight gain in livestock (37) and pose a health risk to humans (26). Additionally, mycotoxin-contaminated grains may be rejected, graded down, and receive lower prices in commerce $(2,26)$. In some years, losses may total several million to one billion dollars in the north-central region of the United States alone (26).

The increased intensity of Fusarium head blight has been attributed to the widespread adoption of conservation tillage practices and the occurrence of favorable weather conditions during periods of greatest host susceptibility $(2,26)$. Conservation tillage results in a substantial amount of crop residue being left on the soil surface. In the U.S. Midwest, maize residue serves as the inoculum source for Fusarium head blight, and wheat planted directly into these residues has a high potential for rapid disease development. Teich and Nelson (40) reported that the average incidence of Fusarium head blight on wheat following maize was six to seven

Corresponding author: L. V. Madden; E-mail address: madden.1@ osu.edu

Publication no. P-2004-1012-01R

(c) 2004 The American Phytopathological Society times greater than that on wheat following soybean or other cereals in a cropping sequence. G. zeae produces ascospores in perithecia on both maize and wheat residues throughout the growing season (1), and inoculum production still may occur even after subjecting residue to conditions favorable for decomposition $(18,39)$. Ascospores, macroconidia, and hyphal fragments all may serve as inoculum for Fusarium head blight development $(2,39)$. However, ascospores and macroconidia are regarded as the inoculum of epidemiological importance because they are considered to be more amenable to dissemination than hyphal fragments (39). Ascospores of G. zeae are released from perithecia during periods of high humidity and moderate temperatures (32) and are dispersed by wind to wheat spikes (10). Macroconidia are widely regarded as being suited for splash dispersal $(30,39)$. Knowledge about the dispersal of ascospores and macroconidia of G. zeae is essential for understanding the epidemiology of Fusarium head blight. After wind dispersal, the second most important means of fungal spore dissemination is splash dispersal (20).

Although the common presence of spores in the air in and around wheat fields indicates that $G$. zeae is disseminated by wind (32), there is strong circumstantial evidence that rain splash is an additional key factor in dispersal of this pathogen. A high correlation between spores collected in Burkhard air samples and spores washed from wheat spikes $(6,29,36)$ is not always present, suggesting that some spores on spikes are dispersed by other means besides wind (12). Large numbers of spores in the air $(4,9,23,34)$ and on wheat spikes $(5,12,24,31)$ often are associated with rain events, suggesting that rain splash is responsible for either (i) spore release from infested debris into the air and onto wheat spikes or (ii) the dispersal of spores previously deposited on leaves (17,30). Furthermore, McMullen et al. (26) attributed 
Fusarium head blight epidemics in North Dakota to the occurrence of above-average rainfall during the period of greatest host susceptibility (flowering). In Canada, Sutton (39) found that epidemics of wheat ear blight caused by $F$. graminearum were associated with years of high rainfall. Strausbaugh and Maloy (38) reported that wheat fields receiving overhead irrigation had a far higher incidence of spikes infected with Fusarium (up to 89\%) than fields which did not receive irrigation. Diseased spikes were not found in nonirrigated fields.

The association among rainfall, inoculum levels in the air and on wheat spikes, and Fusarium head blight intensity suggest that rain does play an important role in disease development. However, the relationship between rainfall and dispersal of G. zeae within wheat canopy has not been investigated. The objectives of this study were to (i) document rain splash dissemination of Fusarium spores under natural conditions and (ii) determine the relationship among incident rain intensity, splashed rain intensity, and splash dispersal of spores.

\section{MATERIALS AND METHODS}

Rain splash sampler and rain splash collection. Rain splash was collected during rain episodes in 2001, 2002, and 2003 in two wheat fields at the Ohio Agricultural Research and Development Center, Wooster, representing locations with different ground cover and potentially different levels of $G$. zeae inoculum. The first location (L1) was a wheat field with maize residue. Wheat was planted after soybean subsequent to conventional tillage. Maize residues saved from a previous crop were spread on the fields to achieve approximately $80 \%$ coverage. Residue levels were determined using the line-transect method (27) and residue was replaced as needed to maintain the desired coverage. The second location (L2) was a wheat screening nursery for Fusarium head blight resistance that was artificially infested with G. zeaeinfested maize kernels.

Inoculum for the nursery was prepared by inoculating sterilized kernels of yellow dent maize with freshly prepared cultures of G. zeae. Five isolates of G. zeae, collected from naturally infected wheat kernels, were transferred to petri dishes containing malt extract agar (MEA) (Fisher Scientific, Pittsburgh) amended with streptomycin sulfate $(0.3 \mathrm{~g} / \mathrm{liter})$, and incubated at room temperature $\left(22\right.$ to $\left.25^{\circ} \mathrm{C}\right)$ for 7 days under a 12 -h photoperiod. Prior to inoculation, $0.8 \mathrm{~kg}$ of kernels were soaked overnight in 0.6 liter of water, then autoclaved for $1 \mathrm{~h}$ on two consecutive days. Inoculation was done by mixing the content of one dish of colonized MEA with every 1.5 liters of kernels. Kernels were incubated at room temperature for approximately 2 weeks until totally colonized. During incubation, each kernel culture was mixed by shaking periodically. Kernels infested by the different isolates were mixed and then spread throughout the nursery at a rate of $36 \mathrm{~g} \mathrm{~m}^{-2}$ 3 weeks prior to the expected anthesis of the earliest wheat lines. Immediately after broadcasting, the field was mist irrigated intermittently on three consecutive days to moisten kernels.

At both locations, splash samplers were placed in $0.5-$ to 0.7-m-wide alleys between adjacent plots. In 2001 and 2002, the rain splash sampler consisted of a sheltered funnel $(13 \mathrm{~cm}$ in diameter) that was attached tightly to a 250 -ml flask. Standard laboratory clamps were used to hold the funnel and the flask to a steel rod driven into the ground and supported vertically. In 2003, the sampler was a sheltered rain gauge (All-Weather Rain Gauge; Forestry Supplies Inc., Jackson, MS) consisting of a top funnel (11 cm in diameter), an outer cylinder, a back plate, and a measuring tube (Fig. 1). In order to collect mostly splash droplets and not incident raindrops, a $30-$ by-30-cm shield or roof was mounted onto the support for each sampler, $30 \mathrm{~cm}$ above the top of the collecting area of the rain gauge. Rain splash was collected at two different heights above the soil surface $(0$ and $30 \mathrm{~cm})$ in 2001 and at three heights $(0,30$, and $100 \mathrm{~cm})$ in 2002 and 2003.
The samplers at the different heights were placed at different positions (approximately $5 \mathrm{~m}$ apart) within each replication. At each location, each height was replicated three times. After each sampled rain episode, the collection vessels were removed and the sample volume was measured and assayed for Fusarium species.

Fusarium spp. identification and weather monitoring. To determine Fusarium spp. abundance, $1 \mathrm{ml}$ of splashed water was transferred under sterile conditions to three replicate dishes containing Komada's medium - an antibiotic-amended, Fusarium-selective medium (7). Cultures were grown at room temperature under alternating 12-h light and dark periods. After 1 week, CFU per dish were counted and categorized based on colony morphology. Sample colonies of each type were transferred to potato dextrose agar (PDA), carrot agar, or carnation leaf agar for identification of Fusarium spp. (28). Numbers of G. zeae colonies, the dominant species, were expressed as $\mathrm{CFU} \mathrm{m} \mathrm{m}^{-1}$ of splashed rain. For convenience, we refer to the number of $\mathrm{CFU} \mathrm{m}{ }^{-1}$ as the number of spores $\mathrm{ml}^{-1}$ of splashed rain, because both ascospores and macroconidia were observed in splash samples.

Adjacent to location L1 and approximately $50 \mathrm{~m}$ from location L2, an automated weather station (Model CR10X; Campbell Scientific Inc., Logan, UT) was deployed to record weather. Sensors placed at canopy level monitored temperature $\left({ }^{\circ} \mathrm{C}\right)$, rainfall $(\mathrm{mm})$, surface wetness ( $\mathrm{k} \Omega$ of electrical resistance, converted to a nominal scale [dry or wet]), relative humidity (\%), wind speed $\left(\mathrm{m} \mathrm{s}^{-1}\right)$, wind direction (degrees), and solar radiation $\left(\mathrm{kJ} \mathrm{m}^{-2} \mathrm{~s}^{-1}\right)$ at 30-min intervals. Rainfall amounts were recorded using a tipping-bucket rain gauge (Model TE525WS; Campbell Scientific Inc.) with a $20-\mathrm{cm}$-diameter collector and a $0.25-\mathrm{mm}$ resolution.

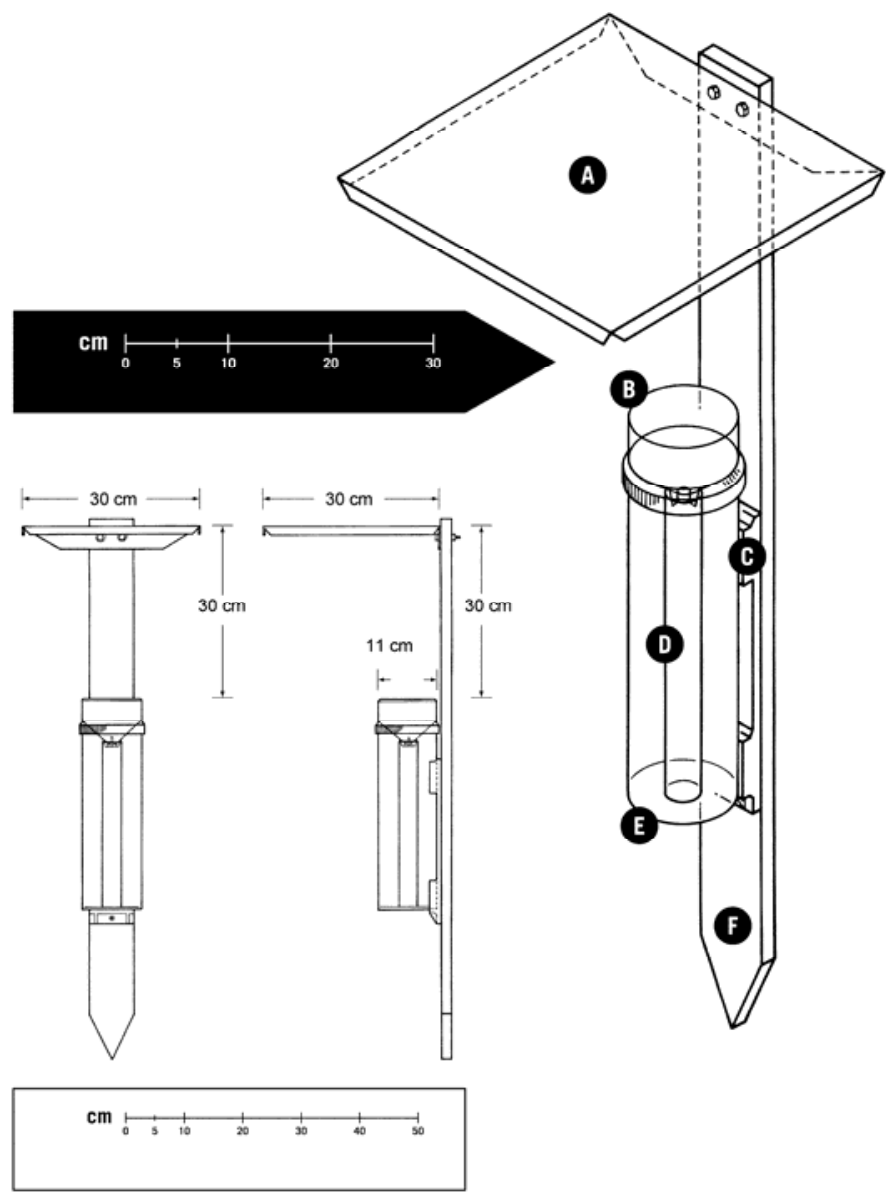

Fig. 1. Sheltered rain splash sampler depicting rain shield (roof) (A), collecting funnel (B), back plate (C), measuring tube (D), outer cylinder (E), and support $(\mathrm{F})$. The images on the lower left show the dimensions and relative positions of the components of the splash sampler. 
Data analysis. Rain splash was collected during 3, 7, and 10 rain episodes in 2001, 2002, and 2003, respectively. Incident and splashed rainfall data were summarized for each sampled rain episode and related to splash dispersal of G. zeae. Total incident rain amount or depth $(\mathrm{mm})$ was simply determined per rain event based on the tipping-bucket rain gauge. Splashed rain depth (mm) was calculated by dividing the volume of splashed water recovered from the sampler by the sampler's horizontal collecting area. Incident rain intensity (IRI; $\mathrm{mm} \mathrm{h}^{-1}$ ) and splashed rain intensity $\left(\mathrm{SRI} ; \mathrm{mm} \mathrm{h}^{-1}\right.$ ) were determined by dividing the depth of incident and splashed rain, respectively, by rainfall duration (h). Both IRI and SRI are types of flux densities of water.

Total spores of $G$. zeae splashed into the sampler at a given height during a rain episode was estimated by multiplying CFU $\mathrm{ml}^{-1}$ by the total milliliters of splashed rain. Spore density per event was determined by dividing this total by the collecting area of the sampler ( $\mathrm{CFU} \mathrm{\textrm {cm } ^ { - 2 }}$ ). Then, spore flux density (SFD) was determined by dividing the spore density per event by the duration of the event (CFU cm$\left.{ }^{-2} \mathrm{~h}^{-1}\right)$. IRI, SRI, and SFD were log- transformed to stabilize variances and obtain linear scales for relationships between variables.

The effects of height (H), location (L), year (Y), and their interactions on logs of SRI and SFD were determined with a linear mixed model (19). These variables all were treated as qualitative factors in the analysis. Depending on the response variable being analyzed, log of SRI or SFD was included as a continuous covariate in the model. In particular, for the analysis of $\log (\mathrm{SRI})$, $\log ($ IRI) was the covariate. For analysis of spores, that is, for $\log (\mathrm{SFD})$ as the response variable, $\log (\mathrm{IRI})$ or $\log (\mathrm{SRI})$ was used as the covariate in separate analyses. Height and location and their interactions were considered fixed effects in the model, and year and all interactions regarding year were considered random effects. Height was a spatially repeated measure. Sampling days within years was considered an additional random-effect blocking factor. Analyses were done using PROC MIXED of SAS (SAS Institute, Cary, NC). Fixed effects were evaluated with $F$ tests based on scaled Wald statistics; random effects were evaluated with standard normal test statistics.
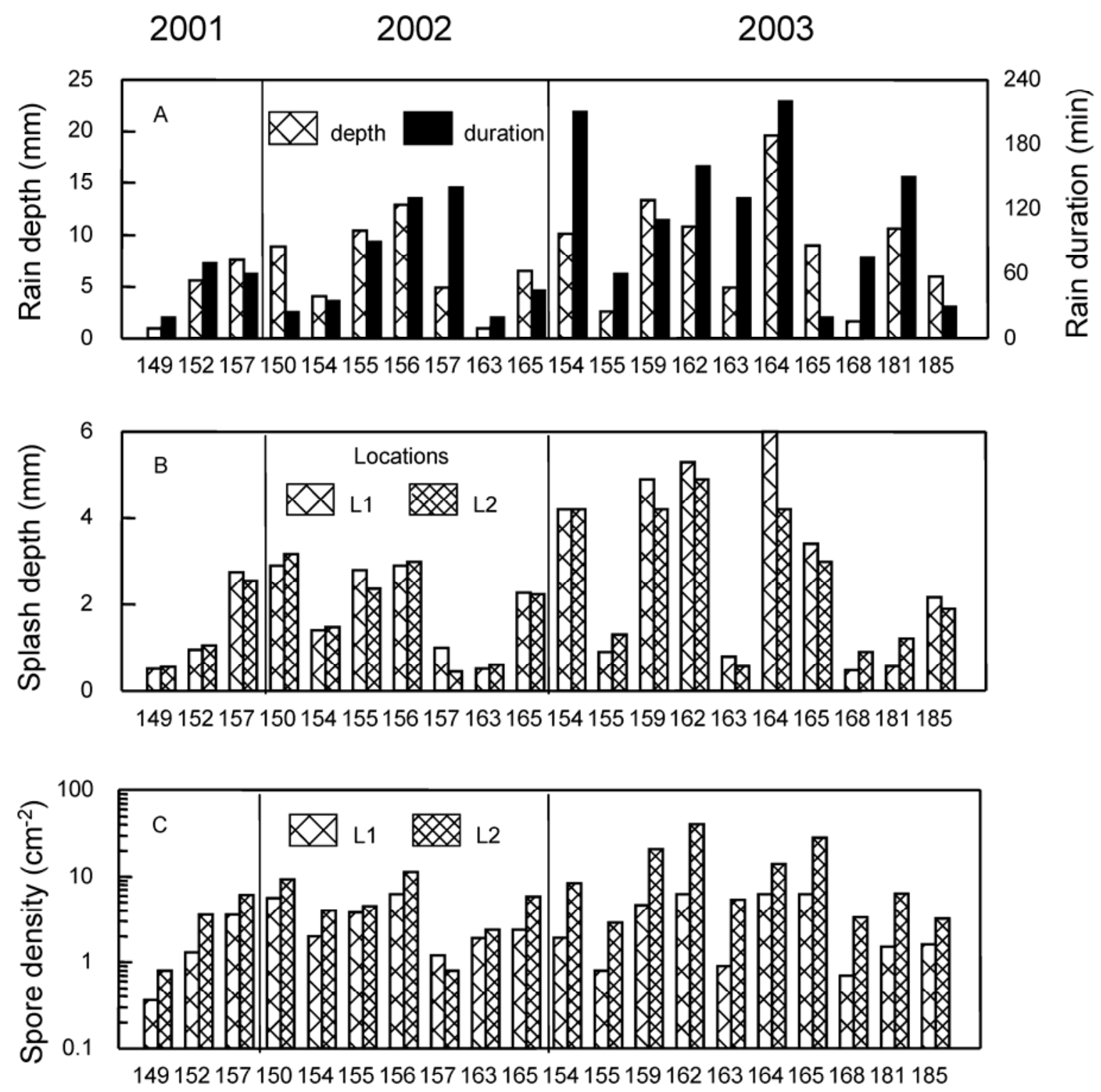

Day of year

Fig. 2. Summary of A, incident rain, B, splashed rain, and C, density of Gibberella zeae spores in rain splash for sampled rain episodes in 3 years (2001, 2002, and 2003). Locations labeled on $\mathbf{B}$ and $\mathbf{C}$ represent wheat field locations with maize residue on the soil surface (L1) and wheat field with G. zeae-infested maize kernels placed on the soil surface (L2). Splash and spore data are averaged across all three sampler heights $(0,30$, and $100 \mathrm{~cm})$ and three replications. 


\section{RESULTS}

Incident and splashed rain. Of the 3 years, 2003 had the highest precipitation, with sampled rain events of longer duration than in 2001 and 2002 (Fig. 2). Incident sampled rain depth ranged from 1 to $7.6 \mathrm{~mm}$ in 2001, 1 to $12.9 \mathrm{~mm}$ in 2002, and 1.7 to $19.6 \mathrm{~mm}$ in 2003. Incident sampled rain duration ranged from 0.3 to $1.2 \mathrm{~h}$ in $2001,0.3$ to $2.3 \mathrm{~h}$ in 2002 , and 0.3 to $3.7 \mathrm{~h}$ in 2003 (Fig. 2). IRI ranged from 3.1 to $7.6 \mathrm{~mm} \mathrm{~h}^{-1}$ in $2001,2.1$ to $21.4 \mathrm{~mm} \mathrm{~h}^{-1}$ in 2002, and 1.4 to $27 \mathrm{~mm} \mathrm{~h}^{-1}$ in 2003. Depth of splashed rain ranged from 0.5 to $2.8 \mathrm{~mm}$ in $2001,0.5$ to $3.17 \mathrm{~mm}$ in 2002, and 0.5 to $6.5 \mathrm{~mm}$ in 2003 (Fig. 2). Similar amounts of splashed rain were collected at both the L1 and L2 locations, and the highest SRI was observed at $100 \mathrm{~cm}$ (Fig. 3). SRI, averaging across the three heights, ranged from 0.8 to $2.6 \mathrm{~mm} \mathrm{~h}^{-1}$ in 2001 , 0.2 to $7.6 \mathrm{~mm} \mathrm{~h}^{-1}$ in 2002 , and 0.5 to $10.2 \mathrm{~mm} \mathrm{~h}^{-1}$ in 2003 . SRI was between 5 and $67 \%$ of the IRI.

The log of SRI was significantly affected by height of the sampler and $\log (\mathrm{IRI})$, but not by year, location, or any interactions (Table 1). Because there were no interactions of the covariable and any qualitative factor, a model for SRI can be written as $\log (\mathrm{SRI})=a_{i}+b \cdot \log (\mathrm{IRI})$ (equation 1 ), where $b$ is the common slope (estimated as 1.073, standard error [se] $=0.072$ ) for all locations, heights, and years, and $a_{\mathrm{i}}$ is the intercept (or line height on a $\log -\log$ scale) for the three sampler heights $(i=0,30$, and $100 \mathrm{~cm})($ Fig. 4A and B). Estimated intercepts were -0.65 (se = $0.065),-0.71$ (se $=0.065)$, and -0.48 (se $=0.065)$ for 0,30 , and $100 \mathrm{~cm}$, respectively. The highest and lowest splash intensities occurred at 100 and $30 \mathrm{~cm}$ above the ground, respectively. Splash at $0 \mathrm{~cm}$ (ground level) was intermediate (Figs. 3 and 4).

Splash dispersal. Based on counted CFU, spores of G. zeae were obtained in the splashed water of every rain event, at both locations, and at all heights over all 3 years. Both ascospores and macroconidia were observed in the splash samples. Total spores in the sampler per rain episode (spore density), averaging across the three heights, ranged from 0.4 to $6.1 \mathrm{CFU} \mathrm{cm}^{-2}$ in $2001,0.8$ to 11.3 CFU cm$~^{-2}$ in 2002, and 0.7 to $40.9 \mathrm{CFU} \mathrm{cm}^{-2}$ in 2003 (Fig. 2). In general, peaks in spore density coincided with peaks in incident rain depth and splashed rain depth at both locations in all 3 years. SFD per rain episode, averaging across the three heights,

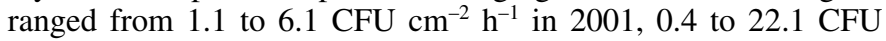
$\mathrm{cm}^{-2} \mathrm{~h}^{-1}$ in 2002 , and 0.4 to $84.8 \mathrm{CFU} \mathrm{cm}^{-2} \mathrm{~h}^{-1}$ in 2003 .

TABLE 1. Probability values (significance levels) from analysis of covariance used to determine the effects of year, location, sampler height, and incident rain intensity (IRI) or splashed rain intensity (SRI) on log of SRI and log of spore flux density (SFD) of Gibberella zeae

\begin{tabular}{lccc}
\hline & \multicolumn{3}{c}{ Dependent variable $^{\mathrm{c}}$} \\
\cline { 2 - 4 } Variables $^{\mathrm{b}}$ & $\log (\mathrm{SRI})$ & $\log (\mathrm{SFD})$ & $\log (\mathrm{SFD})$ \\
\hline Year & $>0.999$ & $>0.999$ & 0.444 \\
Location & 0.369 & 0.024 & 0.067 \\
Height & 0.001 & 0.045 & 0.001 \\
Height $\times$ location & 0.543 & 0.165 & 0.281 \\
Year $\times$ location & 1.000 & 0.118 & 0.167 \\
Year $\times$ height & 0.252 & $>0.999$ & 0.344 \\
$\mathrm{R}$ & $<0.001$ & $<0.001$ & $<0.001$ \\
$\mathrm{R} \times$ location & 0.184 & 0.675 & 0.272 \\
$\mathrm{R} \times$ height & 0.159 & 0.606 & 0.860 \\
$\mathrm{R} \times$ location $\times$ height & 0.595 & 0.087 & 0.251 \\
\hline
\end{tabular}

a Probability values based on $F$ tests for location, height, $\mathrm{R}$, and all interactions involving these variables. $P$ values for year and all interactions involving year (all random effects) were based on standard normal tests.

${ }^{\mathrm{b}}$ Location $=$ sampler location: $\mathrm{L} 1=$ wheat field with $80 \%$ maize residue on the soil surface and L2 = wheat field with $G$. zeae-infested maize kernels on the soil surface; Height $=$ height of splash sampler above the soil surface $(0,30$, and $100 \mathrm{~cm}) ; \mathrm{R}$ is a generic label for rainfall or SRI. $\mathrm{R}=\log (\mathrm{IRI})$ for the relationships between $\log (\mathrm{SRI})$ or $\log (\mathrm{SFD})$ and $\log (\mathrm{IRI})$; and $\mathrm{R}=\log (\mathrm{SRI})$ for the relationship between $\log (\mathrm{SFD})$ and $\log (\mathrm{SRI})$.

c $\mathrm{SRI}=\mathrm{mm} \mathrm{h}^{-1}, \mathrm{IRI}=\mathrm{mm} \mathrm{h}^{-1}$, and SFD $=\mathrm{CFU} \mathrm{cm} \mathrm{ch}^{-1}$.

20012002

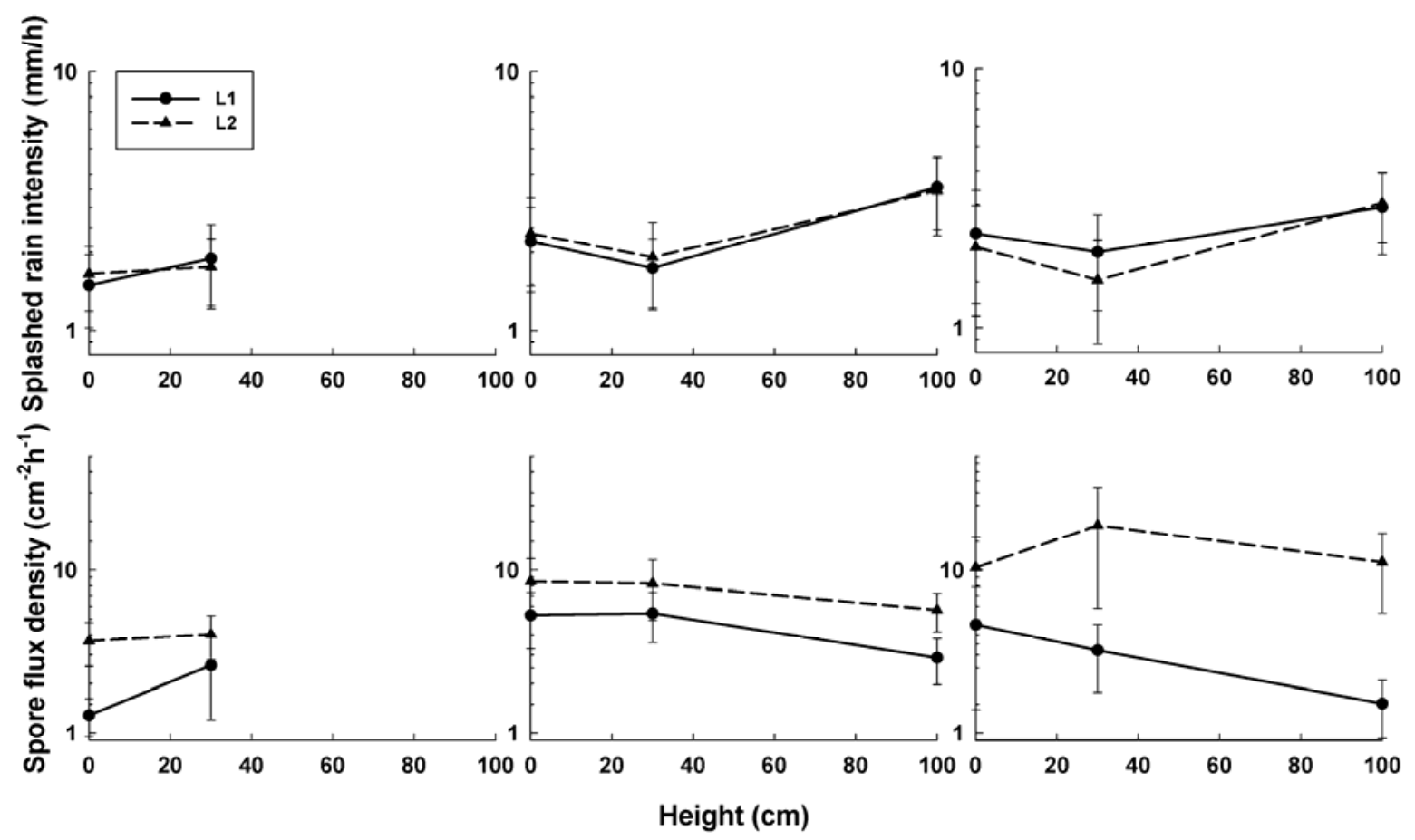

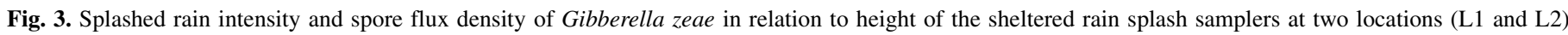

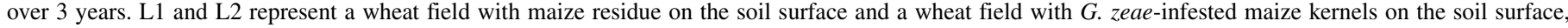

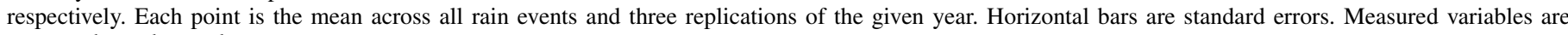
presented on a log scale. 
Both location and height had significant effects on $\log (\mathrm{SFD})$ (Table 1). However, here was no significant effect of year or of any of the interactions of the factors on $\log (\mathrm{SFD})$. There was a slightly lower SFD at $100 \mathrm{~cm}$ than at the other heights (Figs. 3 and $4 \mathrm{C}$ and $\mathrm{E}$ ). Unlike the situation for splashed rain (SRI described previously), there was a large difference in spore dispersal in rain splash between the two locations; in particular, SFD was higher in the wheat nursery (L2) than in the field with maize debris (L1) (Figs. 3 and 4D and F).

In separate analyses, $\log (\mathrm{SFD})$ was found to be significantly related to $\log (\mathrm{IRI})$ and $\log (\mathrm{SRI})$ (Table 1). There were no significant interactions of the covariates and year, location, or height. Thus, a model for SFD can be written as $\log (\mathrm{SFD})=a_{i j}+b \cdot \log (\mathrm{IRI})$ (equation 2 ) and $\log (\mathrm{SFD})=a_{i j}+b \cdot \log (\mathrm{SRI})$ (equation 3 ), in which $b$ is the common slope for all years, locations, and heights, and $a_{i j}$ is the intercept for the three heights $(i=0,30$, and $100 \mathrm{~cm})$ and two locations $(j=1$ and 2$)$. The slope in equation 2 was estimated as 1.17 ( $\mathrm{se}=0.086)$ and the slope in equation 3 as $0.95(\mathrm{se}=0.057)$. Estimated intercepts are given in Table 2. Because there was no interaction between height and location, the difference in intercepts (for a single model fit) between the two locations is the same for the three heights, and the difference between the heights is the same for both locations. The similar SFD values for the 0and $30-\mathrm{cm}$ sampler heights for a given rain or splash intensity is indicated by the very similar intercept values for these heights.

\section{DISCUSSION}

The results of this study constitute the first documented report of a quantitative relationship between rainfall and dispersal of
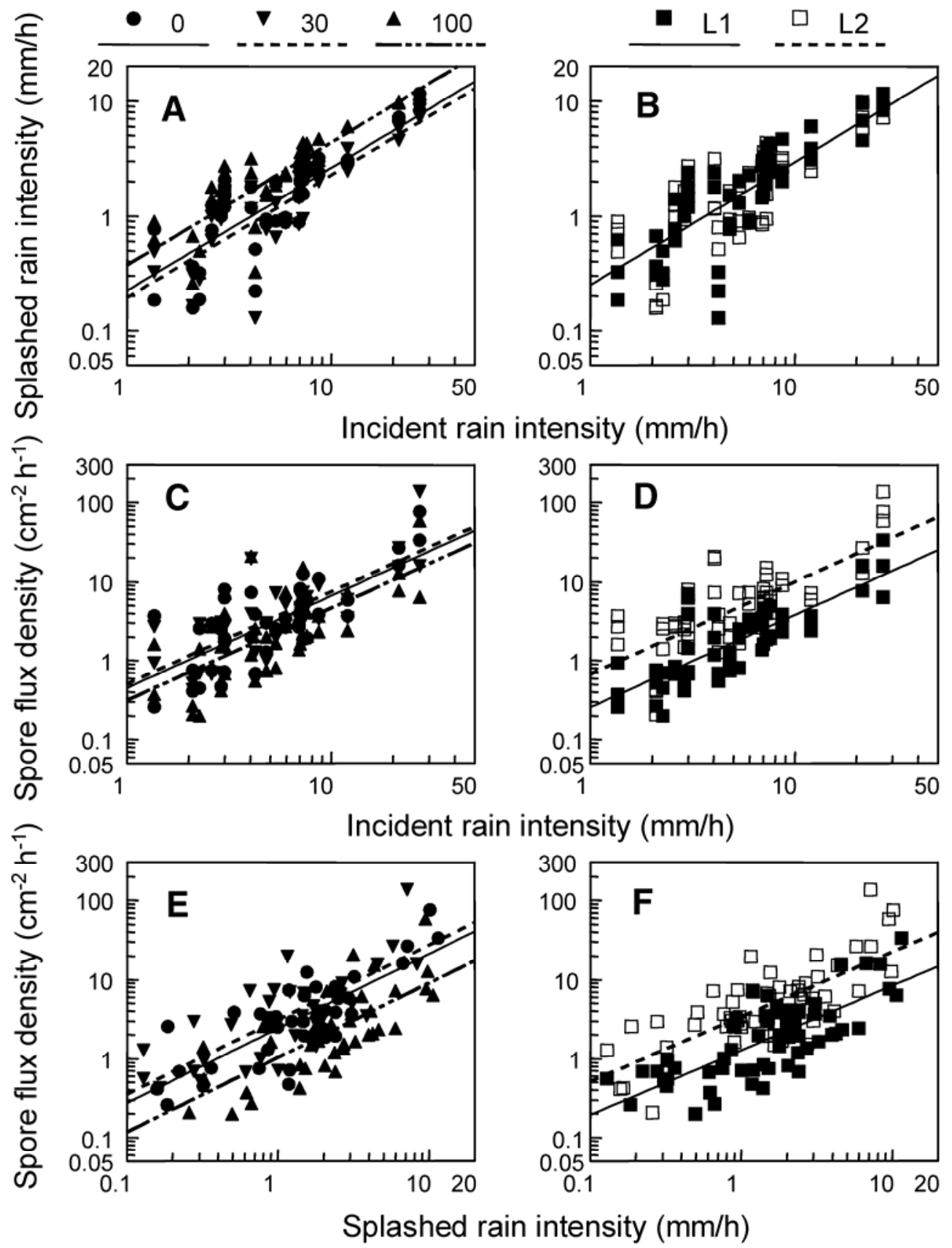

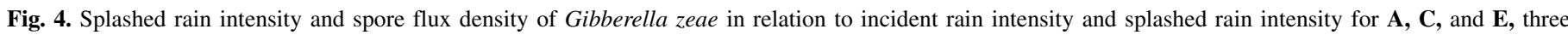
sampler heights and $\mathbf{B}, \mathbf{D}$, and $\mathbf{F}$, two locations. L1 and L2 represent a wheat field with maize residue on the soil surface and a wheat field with G. zeae-infested maize kernels on the soil surface, respectively. Graphs are on a log-log scale. Each point is the mean of three replications for each year, location, height, and rain episode. Lines are based on significant terms of a linear mixed model covariance analysis (Table 1). 
G. zeae. Based on the covariance analysis, we were able to demonstrate a consistent relationship between rainfall and splashed rain and corresponding dispersal of this pathogen. Inoculum was dispersed by rain splash within and around the wheat canopies, and the extent to which this occurred depended on the intensity of incident rain. The intensity of splashed rain was a function of incident rain intensity (IRI), and spore flux density (SFD) was directly related to the intensity of splashed rain in the sampler. Remarkably, splashed rain intensity (SRI) was highest at $100 \mathrm{~cm}$ and SFD was high at all heights and did not decline much with increasing sampler height. This indicates that inoculum of G. zeae is splashed at spike height $(\approx 1 \mathrm{~m})$ in a wheat canopy during rain events.

Splash dissemination of plant-pathogenic fungi involves three fundamental stages: release, movement, and deposition $(3,25)$. The extent to which these processes occur depends on the amount of water and energy transferred during a splash event, the characteristics of the spore-bearing surface being impacted by the rain drops, and the inherent properties of the pathogen being disseminated $(15,25)$. If the incident rain drops have sufficient kinetic energy, splash droplets will be generated and, consequently, spores will be disseminated (21). According to Madden (21), raindrop size is the first determinant of whether or not splash will occur, because there is a strong relationship among drop mass, drop diameter, and kinetic energy. In particular, as rain intensity increases the mean diameter of raindrops also increases $(20,21,43)$, and more splash droplets are generated and spores dispersed by the impact of larger compared with smaller water drops $(11,33,46)$. The strong positive relationships observed between IRI and SRI, SRI and SFD, and IRI and SFD in this study probably were due to the fact that, as IRI increased, so did average incident drop size and kinetic energy, resulting in more splash droplets being generated and more spores being dispersed. This is consistent with other studies. For instance, based on a rain simulation study, Madden et al. (22) and Yang et al. (47) reported that splash dispersal of Colletotrichum acutatum was linearly related to rain intensity. Both the proportion and rate of removal of conidia of $C$. acutatum from the inoculum source increased with rain intensity.

In addition to the characteristics of the incident rain drops, the properties of the inoculum-bearing surface impacted by these drops also may have an effect on splash dispersal (15). However, results of this study suggested that the difference in ground cover between the two locations was not great enough to affect the amount of water splashed into samplers. Similar amounts of splashed rain were collected at both locations and, based on an analysis of covariance, sampler location had no significant effect on the relationship between incident rain intensity (IRI) and splashed rain intensity (SRI). There was, however, a marked effect of sampler location on spore dispersal, indicated by an analysis of spore flux density (SFD). For a given amount of splashed rain,
SFD was higher in the field with artificially infested maize kernels (L2) than in the field with maize residue (L1). There was a larger estimated intercept $\left(a_{i j}\right)$ for location L2 than for location L1 in equations 2 and 3, indicating different line heights for $\log (\mathrm{SFD})$ in Figure 4. This probably reflects differences in the inoculum density in the two fields. In particular, the infested kernels were treated deliberately in the laboratory and field to provide high inoculum production (e.g., use of mist irrigation several days prior to rain sampling).

The height reached by splash droplets also depends on the physical characteristics of the incident drops and the nature of surface impacted by these drops $(44,45)$. Although sampler height had a significant effect on mean SFD, splashed rain and spores of $F$. graminearum were collected at all heights $(0,30$, and $100 \mathrm{~cm})$ at both locations for every rain episode. The results of splash simulation studies conducted using related species of Fusaria, $F$. culmorum, $F$. poae, and $F$. avenaceum $(14,16)$, showed that conidia were splash dispersed to maximum heights of $>45 \mathrm{~cm}$ following the impact of incident drops on conidium-bearing wheat straw. Walklate et al. (45) used simulated rain to demonstrate that droplets generated by incident drops can reach different heights depending on the size of the incident drop and the type of surface impacted. The highest maximum splash heights $(20$ to $60 \mathrm{~cm})$ for single droplets were reached when drops impacted a horizontal surface covered with straw and a naturally accumulating film of water. The characteristics of this surface mimic those of a rainsoaked, residue-covered surface of a field, similar to the ones used in this study. Although natural variation in raindrop size and roughness of the surface can affect the splash process $(15,44,45)$, based on physical principles $(35,44,45)$, direct splashing of droplets from the ground to $100 \mathrm{~cm}$ height is very unlikely. Thus, the consistently high SFD at $100 \mathrm{~cm}$ across years and locations indicates that substantial splashing of water from the upper leaves of the wheat canopy was occurring. Splash generated from drops impacting leaves within the wheat canopy may reach heights of

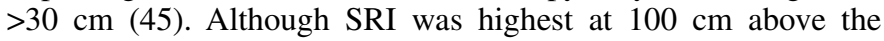
ground, SFD generally was lowest at this height. This probably was indicative of the fact that the principal source of inoculum collected in the samplers was the infested kernels and maize residue on the surface. However, the consistent collection of spores at $100 \mathrm{~cm}$ suggests that inoculum becomes distributed vertically within the canopy during and between rains, so that some spores sampled at $100 \mathrm{~cm}$ likely were splashed from the upper leaves as well as from the ground. It should be noted, however, that the actual amount of inoculum splashed may have been slightly different from the amount estimated in this study. Some amount of incident rain may have entered the sampler, diluting the number of $\mathrm{CFU} \mathrm{ml} \mathrm{m}^{-1}$ of the pathogen. Such sampler contamination most likely would be greatest at $100 \mathrm{~cm}$, where exposure to rain is greatest.

TABLE 2. Estimated intercepts and slopes and their corresponding standard errors (se) for relationships between log of incident rain intensity (IRI) and log of spore flux density (SFD) of Gibberella zeae, and log of splashed rain intensity (SRI) and log of spore flux density (SFD)

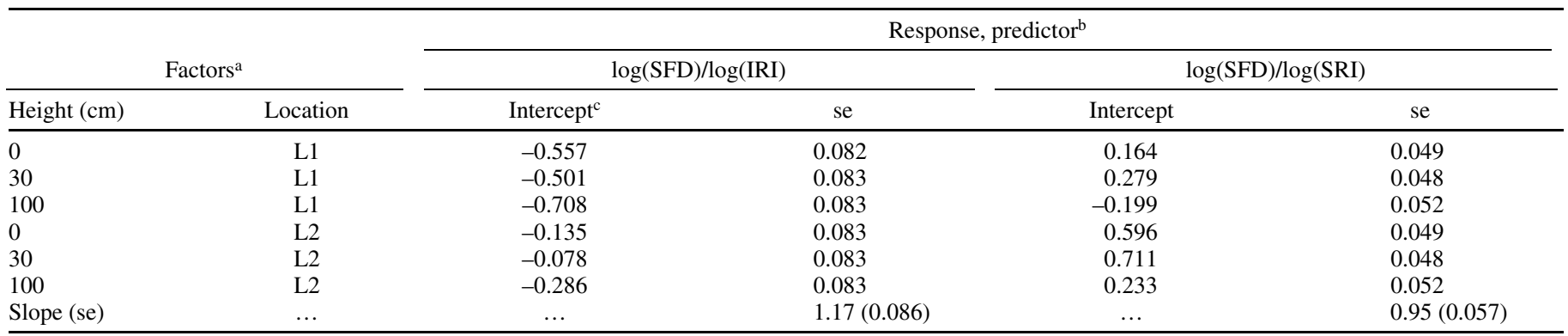

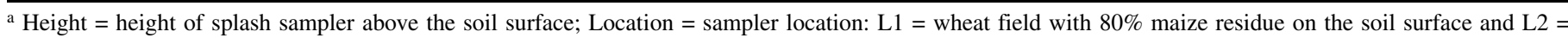
wheat field with G. zeae-infested maize kernels on the soil surface.

b $\mathrm{SFD}=\mathrm{CFU} \mathrm{cm} \mathrm{ch}^{-2} \mathrm{~h}^{-1}, \mathrm{IRI}=\mathrm{mm} \mathrm{h}^{-1}$, and SRI $=\mathrm{mm} \mathrm{h}^{-1}$.

c Intercept estimated from linear mixed model covariance analysis. 
The findings of this study indicate that, in addition to wind dissemination, propagules of $G$. zeae clearly are disseminated by rain splash. This is further supported by the characteristics of the spores produced by, and the nature of the spore-bearing structures of, the causal agent, G. zeae. The macroconidia of this pathogen are smooth, thin-walled, elongated, and borne on sporodochia. These are characteristics typical of splash-dispersed fungi (11). The sequence of events leading to the dispersal of spores produced in mucilaginous clusters (such as sporodochia) involves (i) dissociation of the cluster by rain drops, (ii) formation of a spore suspension in a film of water, and (iii) removal of spores from this film of water by splash droplets (13). Gregory et al. (13) demonstrated that, when a 5-mm-diameter drop of water impacted a macroconidial suspension of $F$. solani (similar to F. graminearum), more than 5,000 droplets were generated and $>50 \%$ of these droplets carried spores. The median horizontal distance traveled by droplets carrying spores was $20 \mathrm{~cm}$. Jenkinson and Parry (17) and Horberg (14) reported that conidia of other related species ( $F$. culmorum, $F$. poae, and $F$. avenaceum) were splash dispersed to maximum horizontal distances of 70 to $100 \mathrm{~cm}$ and maximum heights of 45 to $58 \mathrm{~cm}$ following the impact of incident drops on sporodochium-bearing wheat straw. Ascospores generally are thought to be forcibly discharged through an active mechanism (16) and then carried by wind to wheat spikes (10). However, the moisture conditions suitable for active ascospose release $(32,41)$ do not explain the observed association between rainfall and ascospore abundance in the air $(4,9)$. Along with active discharge, rain also may play a direct and indirect role in the release of ascospores. Rain or moisture also is needed for perithecium development and ascospore maturation $(8,32)$ and, once matured, ascospores may ooze out of the perithecia under high moisture conditions (16). Ingold (16) suggested that it was not uncommon for Pyrenomycetes, the class of Ascomycetes to which G. zeae belongs, typically with an active ascospore discharge mechanism, to produce ascospores which exude in a mucilaginous mass through the ostiole of the perithecium instead of being forcible discharged. Spores produced in mucilaginous masses typically are splash dispersed (11).

Based on the results of this study, we conclude that rain does play an important role in the dispersal of G. zeae and likely in the spread of Fusarium head blight of wheat. Within the wheat canopy, spores consistently are splash dispersed during rainfall events, eventually reaching spike height, and splash dispersal depends on IRI. These findings partly elucidate the well-documented associations observed between rainfall and G. zeae inoculum density and Fusarium head blight intensity. Given that both wind and rain are important for the dissemination of $G$. zeae, further investigations should be carried out to determine the relative importance and the joint contribution of rain- and wind-dispersed inoculum in the epidemiology of Fusarium head blight. The observed relationships between rainfall and inoculum dispersal suggest that spore density within the wheat canopy reasonably could be predicted based on IRI for a given level of inoculum. This information could be used as part of an ongoing effort to make early assessment of the risk of Fusarium head blight in order to guide management decisions.

\section{ACKNOWLEDGMENTS}

Salaries and research support were provided by state and federal funds, especially the United States Wheat and Barley Scab Initiative, to the Ohio Agricultural Research and Development Center, The Ohio State University. We thank W. Bardall and A. Johnston for preparing and maintaining field plots; R. James, R. Berry, and J. Heller for helping to design the splash sampler support apparatus; and J. Ewing for the illustration of the splash sampler (Fig. 1).

\section{LITERATURE CITED}

1. Ayers, J. E., Pennypacker, S. P., Nelson, P. E., and Pennypacker, B. W. 1975. Environmental factors associated with airborne ascospores of Gibberella zeae in corn and wheat fields. (Abstr.) Phytopathology 65:835.

2. Bai, G., and Shaner, G. 1994. Scab of wheat: Prospects for control. Plant Dis. 78:760-766.

3. Campbell, C. L., and Madden, L. V. 1990. Introduction to Plant Disease Epidemiology. John Wiley \& Sons, New York.

4. de Luna, L., Bujold, I., Carisse, O., and Paulitz, T. C. 2002. Ascospore gradients of Gibberella zeae from overwintered inoculum in wheat fields. Can. J. Plant Pathol. 24:457-464.

5. De Wolf, E., El-Allaf, S., Lipps, P., Francl, L., and Madden, L. 2001. Influence of environment on inoculum level and Fusarium head blight severity. Pages 106-109 in: Proc. 2001 Natl. Fusarium Head Blight Forum, Erlanger, KY.

6. De Wolf, E., Francl, L., Lipps, P., Madden, L., Osborne, L., and Jin, Y. 2000. Factors affecting the development of wheat Fusarium head blight. Pages 137-140 in: Proc. 2000 Natl. Fusarium Head Blight Forum, Erlanger, KY.

7. Dhingra, O. D., and Sinclair, J. B. 1985. Basic Plant Pathology Methods. 2nd ed. CRC Press, Boca Raton, FL.

8. Dufault, N. S., De Wolf, E. D., Lipps, P. E., and Madden, L. V. 2003. Influence of temperature and moisture on the Gibberella zeae perithecial development on corn residue. (Abstr.) Phytopathology 93(suppl.):S133.

9. Fernando, W. G. D., Miller, J. D., Seaman, W. L., Seifert, K., and Paulitz, T. C. 1999. Daily and seasonal dynamics of airborne spores of Fusarium graminearum and other Fusarium species sampled over wheat plots. Can. J. Bot. 78:497-505.

10. Fernando, W. G. D., Paulitz, T. C., Seaman, W. L., Dutilleul, P., and Miller, J. D. 1997. Head blight gradient caused by Gibberella zeae from area sources of inoculum in wheat field plots. Phytopathology 87:414421.

11. Fitt, B. D. L., McCartney, H. A., and Walklate, P. J. 1989. The role of rain in dispersal of pathogen inoculum. Annu. Rev. Phytopathol. 27:241-270.

12. Francl, L., Shaner, G., Bergstrom, G., Gilbert, J., Pedersen, W., DillMacky, R., Sweets, L., Corwin, B., Jin, Y., Gallenberg, D., and Wiersma, J. 1999. Daily inoculum levels of Gibberella zeae on wheat spikes. Plant Dis. 83:662-666.

13. Gregory, P. H., Guthrie, E. J., and Bunce, M. E. 1959. Experiments on splash dispersal of fungus spores. J. Gen. Microbiol. 20:328-354.

14. Horberg, M. H. 2002. Pattern of splash dispersed conidia of Fusarium poae and Fusarium culmorum. Eur. J. Plant Pathol. 108:73-80.

15. Huber, L., Madden, L. V., and Fitt, B. D. L. 1998. Rain-splash and spore dispersal: A physical perspective. Pages 348-370 in: The Epidemiology of Plant Diseases. D. Gareth Jones, ed. Kluwer Academic Publishers, Dordrecht, The Netherlands.

16. Ingold, C. T. 1933. Spore discharge in the Ascomycetes. I. Pyrenomycetes. New Phytol. 32:175-196.

17. Jenkinson, P., and Parry, D. W. 1994. Splash dispersal of conidia of Fusarium culmorum and Fusarium avenaceum. Mycol. Res. 98:506-510.

18. Khonga, E. B., and Sutton, J. C. 1988. Inoculum production and survival of Gibberella zeae in maize and wheat residues. Can. J. Plant Pathol. 10:232-239.

19. Littell, R. C., Milliken, G. A., Stroup, W. W., and Wolfinger, R. D. 1996. SAS System for Mixed Models. SAS Institute, Cary, NC.

20. Madden, L. V. 1992. Rainfall and dispersal of fungal spores. Adv. Plant Pathol. 8:39-79.

21. Madden, L. V. 1997. Effects of rain on splash dispersal of fungal pathogens. Can. J. Plant Pathol. 19:225-230.

22. Madden, L. V., Yang, X., and Wilson, L. L. 1996. Effects of rain intensity on splash dispersal of Colletotrichum acutatum. Phytopathology 86:864-874.

23. Markell, S., and Francl, L. 2001. Dynamics of Gibberella zeae ascospore dispersal. (Abstr.) Phytopathology 91(suppl.):S58.

24. Markell, S., and Francl, L. 2003. Fusarium head blight inoculum: Species prevalence and Gibberella zeae spore type. Plant Dis. 87:814-820.

25. McCartney, H. A. 1994. Spore dispersal: Environmental and biological factors. Pages 171-185 in: Ecology of Plant Pathogens. J. P. Blakeman and B. Williamson, eds. CAB International Publishing, Wallingford, UK.

26. McMullen, M., Jones, R., and Gallenburg, D. 1997. Scab of wheat and barley: A re-emerging disease of devastating impact. Plant Dis. 81:13401348.

27. Midwest Plan Service. 1992. Conservation tillage systems and management. Iowa State Univ. Publ. MWPS-45.

28. Nelson, P. E., Toussoun, T. A., and Marasas, W. F. O. 1983. Fusarium Species: An Illustrated Manual for Identification. The Pennsylvania State University, University Park.

29. Osborne, L., Yin, Y., and Kohl, R. 2000. Fusarium head blight: Inoculum detection, disease progress, and environmental influence. Pages 163-168 in: Proc. 2000 Natl. Fusarium Head Blight Forum, Erlanger, KY. 
30. Parry, D. W., Jenkinson, P., and McLeod, L. 1995. Fusarium ear blight (scab) in small grain cereals-A review. Plant Pathol. 44:207-238.

31. Paul, P. A., El-Allaf, S. M., Lipps, P. E., and Madden, L. V. 2003. Development of Fusarium head blight of winter wheat in Ohio as influenced by planting date, cultivar maturity, and inoculum level. Pages 156-159 in: Proc. 2003 Natl. Fusarium Head Blight Forum, Bloomington, MN.

32. Paultiz, T. C. 1996. Diurnal release of ascospores by Gibberella zeae in inoculated wheat plots. Plant Dis. 80:674-678

33. Reynolds, K. M., Madden, L. V., Reichard, D. L., and Ellis, M. A. 1989. Splash dispersal of Phytophthora cactorum from infected strawberry fruit by simulated canopy drip. Phytopathology 79:425-432.

34. Rossi, V., Languasco, L., Pattori, E., and Giosue, S. 2002. Dynamics of airborne Fusarium macroconidia in wheat fields naturally affected by head blight. J. Plant Pathol. 84:53-64.

35. Saint-Jean, S., Chelle, M., and Huber, L. 2004. Modelling water transfer by rain-splash in a 3D canopy using Monte Carlo integration. Agric. For. Meteorol. 121:183-196.

36. Shaner, G., and Buechley, G. 2000. Sampling spores of Fusarium graminearum. Pages 182-186 in: Proc. 2000 Natl. Fusarium Head Blight Forum, Erlanger, KY.

37. Snijders, C. H. A. 1990. Fusarium head blight and mycotoxin contamination of wheat, a review. Neth. J. Plant Pathol. 96:187-198.

38. Strausbaugh, C. A., and Maloy, O. M. 1986. Fusarium scab of irrigated wheat in Central Washington. Plant Dis. 70:1104-1106.
39. Sutton, J. C. 1982. Epidemiology of wheat head blight and maize ear rot caused by Fusarium graminearum. Can. J. Plant Pathol. 4:195-209.

40. Teich, A. H., and Nelson, K. 1984. Survey of Fusarium head blight and possible effects of cultural practices in wheat fields in Lambton county in 1983. Can. Plant Dis. Surv. 64:11-13.

41. Tschanz, A. T., Horst, R. K., and Nelson, P. E. 1975. Ecological aspects of ascospore discharge in Gibberella zeae. Phytopathology 65:597:599

42. Tuite, J., Shaner, G., and Everson, R. J. 1990. Wheat scab in soft red winter wheat in Indiana in 1986 and its relation to some quality measures. Plant Dis. 74:959-962.

43. Ulbrich, C. W. 1983. Natural variations in the analytical form of the raindrop distribution. J. Clim. Appl. Meteorol. 22:1764-1775.

44. Walklate, P. J. 1989. Vertical dispersal of plant pathogens by splashing Part I: The theoretical relationship between rainfall and upward splash. Plant Pathol. 38:56-63.

45. Walklate, P. J., McCartney, H. A., and Fitt, B. D. L. 1989. Vertical dispersal of plant pathogens by splashing. Part II: Experimental study of the relationship between raindrop size and the maximum splash height. Plant Pathol. 38:64-70.

46. Yang, X., Madden, L. V., Reichard, D. L., Fox, R. D., and Ellis, M. A 1991. Motion analysis of drop impaction on a strawberry surface. Agric. For. Meteorol. 56:67-92.

47. Yang, X., Madden, L. V., Wilson, L. L., and Ellis, M. A. 1990. Effects of surface topography and rain intensity on splash dispersal of Colletotrichum acutatum. Phytopathology 80:1115-1120. 